Article

\title{
Magnetoelectric Plasma Preparation of Silicon-Carbon Nanocomposite as Anode Material for Lithium Ion Batteries
}

\author{
Fangfang Wang ${ }^{1}$, Maochuan Gao ${ }^{1}$, Ruoyu Hong ${ }^{1, * \mathbb{D}}$ and Xuesong Lu ${ }^{2}$ \\ 1 College of Chemical Engineering, Fuzhou University, Fuzhou 350108, China; wffruoli@163.com (F.W.); \\ mc_gao1938883211@163.com (M.G.) \\ 2 School of Engineering and Physical Sciences, Heriot-Watt University, Edinburgh EH14 4AS, UK; \\ L.Xuesong@hw.ac.uk \\ * Correspondence: rhong@fzu.edu.cn
}

Received: 3 March 2020; Accepted: 1 April 2020; Published: 13 April 2020

\begin{abstract}
A high-performance silicon-carbon nanocomposite facilely prepared by one-step magnetoelectric plasma pyrolysis of the mixture of methane, silane, and hydrogen is proposed for lithium-ion batteries. The ratio of silane, methane, and hydrogen was studied to optimize the properties of the composite. When the ratio of hydrogen/silane/methane is 1:1:3, the composite is composed of spherical Si nanoparticles that uniformly attach to the surface of the tremelliform carbon nanosheets framework, in which the tremelliform carbon nanosheets can effectively resist the volumetric change of the Si nanoparticles during the cycles and serve as electronic channels. The silicon-carbon nanocomposite exhibits a high reversible capacity (1007 $\mathrm{mAh} \mathrm{g}^{-1}$ after 50 cycles), a low charge transfer resistance, and an excellent rate performance. In addition, the proposed process for synthesizing silicon-carbon nanocomposite without expensive materials or toxic reagents is an environmentally friendly and cost-effective method for mass production.
\end{abstract}

Keywords: silicon-carbon nanocomposite; anode; lithium ion batteries; DC magnetoelectric plasma

\section{Introduction}

Nowadays, lithium-ion batteries (LIB) are the fastest developing energy storage systems, and have widespread application in mobile phones, laptops, electric vehicles, etc. [1-3]. However, the commercial graphite anode material has a limited theoretical capacity of $372 \mathrm{mAh} \mathrm{g}^{-1}$, which cannot meet the energy density requirements in certain applications [4,5]. Various studies have been carried out to find new high energy density materials, such as Sn- [6,7] or Si-based anodes [8-10], and transition metal oxides [11,12]. Among these, Si-based material is considered as a promising candidate owing to its high theoretical capacity of $4200 \mathrm{mAh} \mathrm{g}^{-1}[13,14]$. At present, the main challenge is the enormous volumetric change of the Si during the cycle process, leading to structural failure and pulverization $[15,16]$, and the low electronic conductivity of silicon also induces severe irreversible capacity loss.

At present, research has mainly focused on finding new Si-based structures to solve the problems of the volumetric changes. The utility of nanoparticles, nanosheets, nanohollows, nanowires, and nano-core-shells has been studied as well [17-21]. Among them, silicon/carbon composites are regarded as effective structures to alleviate the volumetric changes of the silicon. In them, the silicon acts as the active material to provide lithium storage capacity, and the carbon material acts as a buffer to resist the volumetric changes of silicon during the cycle process. In addition, the drastic capacity fading of the Si-based anode corresponds to the solid electrolyte interphase (SEI) films repeatedly formed during the cycles. It has been proved that the surrounding carbon material avoids direct contact between the silicon and the electrolyte, preventing repeated SEI formation [22-24]. 
To develop a high-performance anode material, Park et al. [25] synthesized a Si/carbon/graphite composite, and the Si nanoparticles were encapsulated by the carbonized coal-tar pitch and attached to the surface of graphite; the amorphous carbon layer avoided the direct contact between the $\mathrm{Si}$ nanoparticles and electrolyte and alleviated the volumetric changes of the Si nanoparticles during the cycles. The specific capacity of the composite was $712 \mathrm{mAh} \mathrm{g}^{-1}$ at a current density of $130 \mathrm{~mA} \mathrm{~g}^{-1}$, with a capacity retention of $80 \%$ after 100 cycles [25]. Wang et al. [26] proposed a sandwich-structured silicon nanoparticle/hollow graphite fiber/carbon-coated composite. In this work, the volume expansion of the Si nanoparticles was effectively controlled by the new sandwich-structure, and the specific capacity of the composite was maintained at $910.1 \mathrm{~mA} \mathrm{~h} \mathrm{~g}^{-1}$ after the 50th cycle.

Most silicon-carbon nanocomposites are embedded structures and are prepared by high-temperature pyrolysis of carbon materials, in which the Si nanoparticles are encapsulated by amorphous carbon layers to resists the volumetric change and enhance electrode conductivity. However, the further improvement of the electrochemical performance is limited by the non-uniform thickness of carbon coating and serious agglomeration of Si nanoparticles [27,28]. Moreover, the complex process, reagent pollution, and high cost make it difficult for industrialization.

Recently, plasma technology has been introduced to prepare silicon-carbon nanocomposites due to the rapid synthesis process without expensive materials or toxic reagents. However, the traditional plasma technology for the preparation of silicon-carbon nanocomposite is inadequate to achieve mass production. Herein we proposed a novel plasma process with a magnetron plasma generator, in which the addition of magnetic force increases the volume and density of the plasma reaction region and reduces energy consumption. Thus, it lays a good foundation for mass production. The silicon-carbon nanocomposite was prepared by one-step magnetoelectric plasma pyrolysis of the mixture of methane, silane, and hydrogen, in which methane acts as the carbon source, silane as the silicon source, hydrogen as the reducing gas, and argon as the carrier gas. Finally, a new composite structure was obtained in which the evenly dispersed Si nanoparticles were adsorbed on the surface of tremelliform carbon nanosheets, effectively preventing the aggregation and volume expansion of the Si nanoparticles and showing excellent electrochemical performance.

\section{Experimental}

\subsection{Material Preparation}

In order to achieve mass production of the silicon-carbon nanocomposite, a new magnetron plasma device was designed to expand the plasma region (Figure 1a). The device consists of a high-voltage DC external power supply, a cylindrical high-temperature insulated reactor, and a separation device. In the reactor, the tungsten electrode (positive electrode) is attached to the top with an insulation plug, and the graphite ring electrode (negative electrode) is fixed vertically with respect to the tungsten electrode. The separation device is connected to the reactor, which can separate the product from tail gas. In the experiment, an easy-to-ionized gas (argon) was used as the carrier gas, methane as the carbon source, silane as the silicon source, hydrogen as the reducing gas, and the tangential air inlet is used for gas to rotate after entering the plasma discharge device. A probe unit was used to detect the leakage of gas pipeline to ensure the airtightness.

After cleaning the reaction system with argon, the mixture of methane, silane, and hydrogen was injected into the plasma reactor in a certain proportion under carrier gas. When the DC high-voltage $(8000 \mathrm{~V})$ power supply was turned on, the arc was triggered between the positive and negative electrodes. Under the magnetic field, the arc rotates in the wide range of the plasma region as show in Figure 1b. Plasma actions as the high-heat source and chemically active particle in the preparation of nanomaterials. The methane and silane break into many electriferous intermediates in the high-intensity electric field, and some of the intermediates are the precursors for tremelliform carbon nanosheets and Si nanoparticles. The powdered material was produced instantly and collected 
in the separation device. After the reaction, the silane pipeline was purged with argon gas, and the unreacted silane in the tail gas was absorbed by the alkali lye.

The plasma device has the following advantages: (1) The arc rotation is controlled by the magnet field to produce a high volume full of plasma; at the same time, the rotation of the arc makes the temperature and intensity distribution of the plasma uniform as well as a sustainable reaction. All these improve the conversion and yield. (2) The electrode temperature is decreased, and the possibility of damaging the electrode can be alleviated by the rotation of the arc. (3) The tail gas can be recycled.
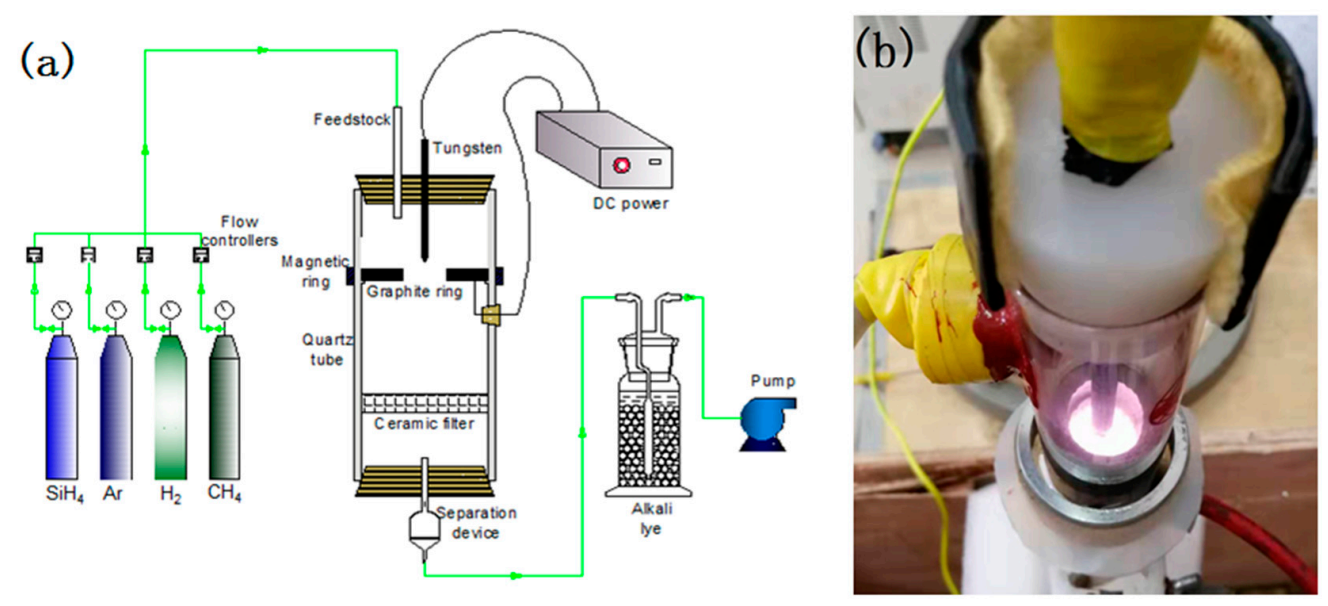

Figure 1. DC magnetoelectric plasma installation. (a) Schematic diagram, (b) Discharge device.

\subsection{Material Characterization}

The morphology of the material was characterized with a scanning electron microscope (SEM S-4800, Hitachi, Tokyo, Japan) using an accelerating voltage of $10 \mathrm{kV}$. The crystal structure of the material was obtained by X-ray powder diffraction (XRD DY5261/Xpert3, PANalytical B.V., Almelo, The Netherlands) with $\mathrm{Cu} K \alpha$ radiation; the scan range was 10 to $90^{\circ}$, and the scanning speed was $0.2^{\circ} \%$. Raman spectroscopy (inVia Refelx, ReniShawn, London, English) was performed at the excitation wavelength of $457.9 \mathrm{~nm}$, and the scan range was 400 to $2000 \mathrm{~cm}^{-1}$.

\subsection{Electrochemical Characterization}

To evaluate the electrochemical performance of the silicon-carbon nanocomposite, the CR2025 coin cells were assembled in an argon-filled glove box. The working electrodes consisted of $80 \mathrm{wt} \%$ active material (silicon-carbon nanocomposite), $10 \mathrm{wt} \%$ carbon black (Super-P), and $10 \mathrm{wt} \%$ sodium alginate. A uniform and stable slurry was obtained by ball milling, which was then spread onto the copper foil and dried at $120^{\circ} \mathrm{C}$ for $8 \mathrm{~h}$ under vacuum until the distilled water was entirely removed. The lithium foil was the counter electrode, the polypropylene membrane (Celgard 2400) was the separator, and the electrolyte was $1 \mathrm{M} \mathrm{LiPF}_{6}$ in a mixture of ethylene carbonate (EC) and dimethyl carbonate (DMC) (1:1 by volume).

The cycling experiments were performed in the voltage range between 0.01 and $1.5 \mathrm{~V}\left(\mathrm{vs} . \mathrm{Li} / \mathrm{Li}^{+}\right)$on CT2001A (LAND, Bart Rui Tech. Co., Ltd., Beijing, Chian) battery testers. Electrochemical impedance spectroscopy (EIS) tests were performed from $1 \mathrm{MHz}$ to $0.1 \mathrm{~Hz}$ with a $5-\mathrm{mV}$ amplitude signal range, and the cyclic voltammetry $(\mathrm{CV})$ measurements were performed at a scan rate of $0.1 \mathrm{mV} \mathrm{s}^{-1}$ between 0 and $2.0 \mathrm{~V}\left(\mathrm{vs} . \mathrm{Li} / \mathrm{Li}^{+}\right.$). Both were recorded using the Gamry electrochemical system (Interface1010E).

\section{Results and Discussion}

\subsection{Yields under Different Carrier Gas Flow}

Figure 2 shows the yield of nanosized composite under different carrier gas (argon) flows with a certain flow of reaction gas (methane and silane). All the samples were collected under the same 
experimental conditions and tested by parallel experiments. When the mixture enters the plasma region under the carrier gas, it first breaks into many electriferous intermediates in the electric field, and these intermediates polymerize at the molecular scale and then nucleate and grow. Finally, the product is carried out of the plasma by the carrier gas. When the carrier gas flow is very low $(<4000 \mathrm{~mL} / \mathrm{min})$, it is difficult to rotate the arc, resulting in high concentration of plasma and high temperature of the arc. Excessive temperature will cause the free radicals obtained by pyrolysis of silane and methane to reform into gaseous products instead of solid products. As the carrier gas flow increases, the arc starts to rotate, and the reaction gas/carrier gas ratio is more suitable for pyrolysis. The optimum carrier gas flow appears at $7000 \mathrm{~mL} / \mathrm{min}$. Under this condition, the maximum yield reaches $5.6 \mathrm{~g} / \mathrm{h}$. However, further increase of the carrier gas flow would lead to a decrease in yield. This is because a higher carrier gas flow shortens the residence time of methane or silane in the plasma [29]. Because of that, methane or silane cannot be pyrolyzed effectively. The experimental results in this work are consistent with previous studies [30].

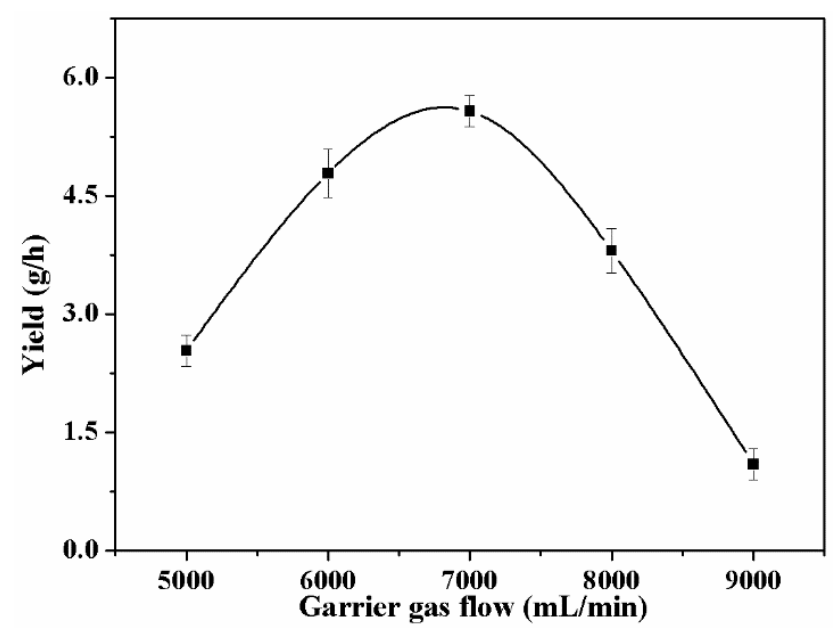

Figure 2. Yield of solid products under different carrier gas flows.

\subsection{Effect of Silane/Methane Ratio on Silicon-Carbon Nanocomposite}

The Si nanoparticles act as a high energy store, and the carbon materials are expected to prevent the pulverization of the Si nanoparticles. Low silicon content will reduce the theoretical capacity of the composite, and low carbon content cannot restrain the volume changes of the silicon well. Therefore, the appropriate silicon-carbon ratio directly affects the electrochemical properties of the composite. Under the condition with a voltage of $8000 \mathrm{~V}$, carrier gas flow of $6000 \mathrm{~mL} / \mathrm{min}$, and methane flow of $360 \mathrm{~mL} / \mathrm{min}$, the silicon-carbon nanocomposite was prepared with different silane and methane ratios. The ratio of silane to methane was $0: 1,1: 10,1: 5,1: 3,1: 2$, and 1:0, respectively, and the optimal ratio of silane to methane was determined to be 1:3.

Figure 3 shows the cycling stability of these six composites at a current of $150 \mathrm{~mA} \mathrm{~g}^{-1}$. It can be seen that the discharge capacity generally improves rapidly as the silane ratio increases, and then tends to decline. In terms of pure tremelliform carbon nanosheets, the specific capacity of the electrode is stabilized at $343 \mathrm{mAh} \mathrm{g}^{-1}$ after 50 cycles. With the addition of the silane, the specific capacity of the silicon-carbon nanocomposite increases significantly. As the ratio of silane to methane increases from 1:10 to 1:3, the specific capacity of the composite changes from 539 to $948 \mathrm{mAh} \mathrm{g}^{-1}$ after 50 cycles. However, when the ratio of silane to methane increases to 1:2, the discharge-specific capacity tends to decline. This may be because the amount of carbon materials is not sufficient to alleviate the volume change of the Si nanoparticles during the cycles, and the electrolyte decomposition repeatedly forms the SEI film on the Si nanoparticles surface during the cycles, which consumes a large amount of $\mathrm{Li}^{+}$and leads to a decrease in the specific capacity ( $831 \mathrm{mAh} \mathrm{g}^{-1}$ after 50 cycles). A quick capacity fading is observed in the pure Si nanoparticles, which further suggests that the Si nanoparticles rapidly 
pulverize without the buffering effect of carbon materials. Above all, the optimal ratio of silane to methane is 1:3, and under this condition, the composite exhibits a higher stable specific capacity.

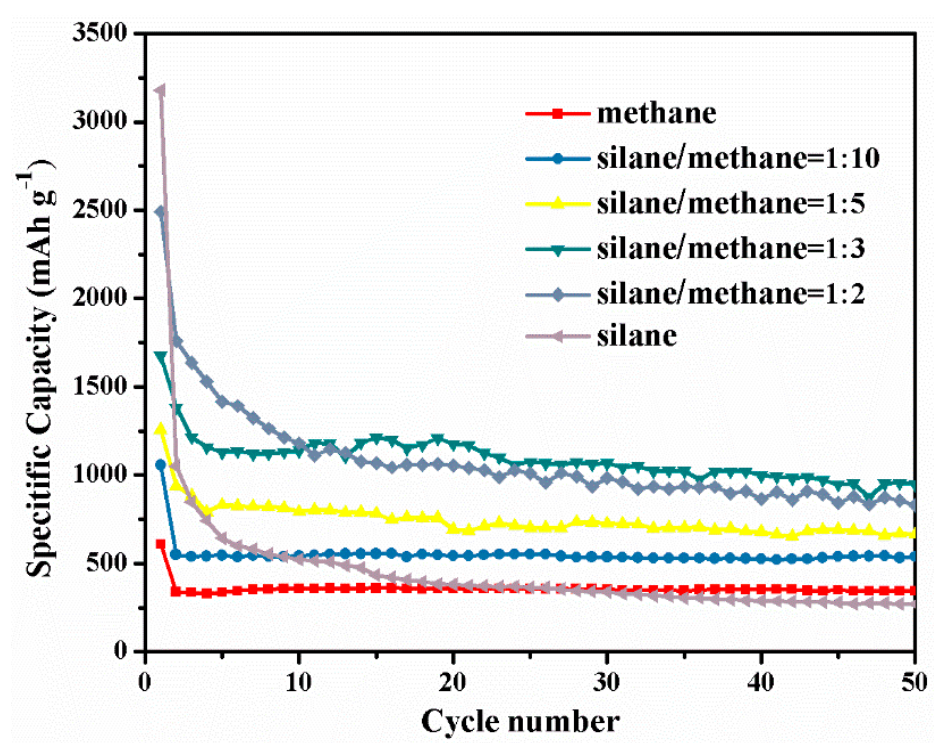

Figure 3. Cyclic performance of the silicon-carbon nanocomposite prepared under different silane/methane ratios at $150 \mathrm{~mA} \mathrm{~g}^{-1}$ between 0.01 and $1.5 \mathrm{~V}$.

\subsection{Effect of Hydrogen on Silicon-Carbon Nanocomposite}

According to previous research, carbon black can be obtained by plasma pyrolysis of methane [31], while graphene can be further prepared by adding an appropriate ratio of hydrogen [32]. As for the effect of hydrogen, our research group has carried out in-depth research [32], through simulation, it was found that the addition of hydrogen can generate a large number of hydrogen atoms, which can form C-H bonds with carbon atoms on the edge of the carbon cluster, resulting in the decrease of carbon dangling bonds, and delaying the formation of spherical particles in the carbon cluster. Related studies have reported that the formed hydrogen atoms can react with the carbon cluster and form bonds, terminating the carbon-centered free radical to form sheet-like carbon materials [33]. On this basis, adding hydrogen is expected to prepare a new composite structure containing tremelliform carbon nanosheets, which could effectively buffer the volumetric changes of Si nanoparticles. Therefore, the influence of the hydrogen flow rate on the properties of the silicon-carbon nanocomposite was investigated under the conditions of a DC input voltage of $8000 \mathrm{~V}$, a carrier gas flow of $6000 \mathrm{~mL} / \mathrm{min}$, silane flow rate of $120 \mathrm{~mL} / \mathrm{min}$, and methane flow rate of $360 \mathrm{~mL} / \mathrm{min}$.

Figure 4 shows the SEM images of the composites prepared under the different rates of hydrogen to methane $(0: 1,1: 20,1: 10,1: 5,1: 3$, and 1:2). As shown in Figure 4a, without the addition of hydrogen, the products are mainly spherical carbon and silicon nanoparticles with uneven dispersion. After the hydrogen is injected, the spherical carbon material becomes significantly larger and tends to tremelliform. Meanwhile, the Si nanoparticles and carbon materials are dispersed well (Figure 4b). When the ratio of hydrogen to methane increases, the proportion of the tremelliform carbon increases dramatically (Figure $4 c, d$ ). When the ratio of hydrogen to methane increases to 1:3 (Figure 4e), almost all of the carbon materials are tremelliform nanosheets, as the carbon changes from a spherical to a tremelliform nanosheet structure, the Si nanoparticles are dispersed much better among the tremelliform carbon nanosheets. The volume changes of Si nanoparticles can be effectively restrained by the tremelliform carbon nanosheets during the cycles. As the ratio of hydrogen to methane increases from 1:3 (Figure 4e) to 1:2 (Figure 4f), the structure of the composite remains basically unchanged. Because of that, the optimal ratio of hydrogen to methane is 1:3. 

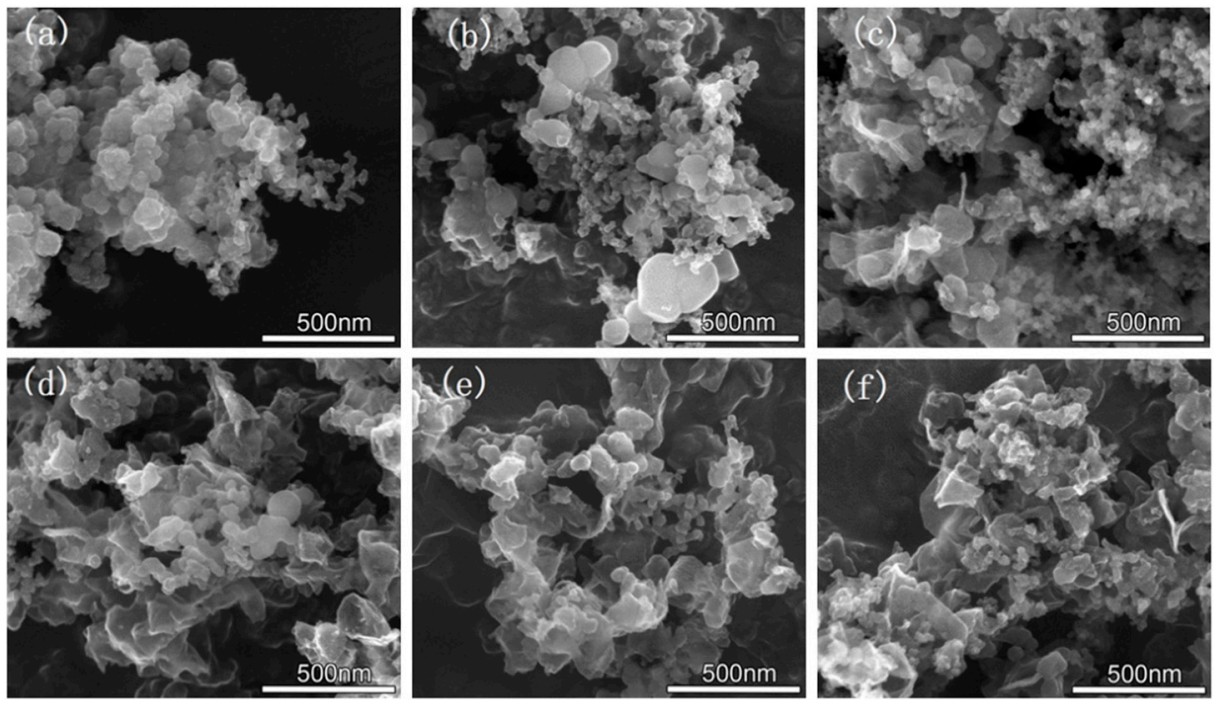

Figure 4. SEM images of the silicon-carbon nanocomposite prepared with different hydrogen/methane ratios. (a) No hydrogen, (b) 1:20, (c) 1:10, (d) 1:5, (e) 1:3, (f) 1:2.

\subsection{Characterization of the Silicon-Carbon Nanocomposite}

The detailed morphology, structure, and composition of the silicon-carbon nanocomposite prepared under the optimal conditions in this work were characterized. Figure 5 shows the SEM images of the different products prepared by the DC magnetoelectric plasma system. Figure 5a shows the spherical pure Si nanoparticles (size is in the range of 50-100 nm, under the ratio of hydrogen/silane of 1:1), the size distribution of the Si nanoparticles (inset) was obtained by analyzing the SEM image using SigmaScan software. Figure $5 \mathrm{~b}$ shows the pure tremelliform carbon nanosheets (with a size of 200-400 nm, ratio of hydrogen/methane of 1:3). Figure 5c,d show the SEM images of the silicon-carbon nanocomposite prepared under the optimal condition (ratio of hydrogen/silane/methane of 1:1:3). It is obvious that the spherical Si nanoparticles are evenly dispersed among the tremelliform carbon nanosheets., which can effectively alleviate the agglomeration and volumetric change of Si nanoparticles during the cycles.
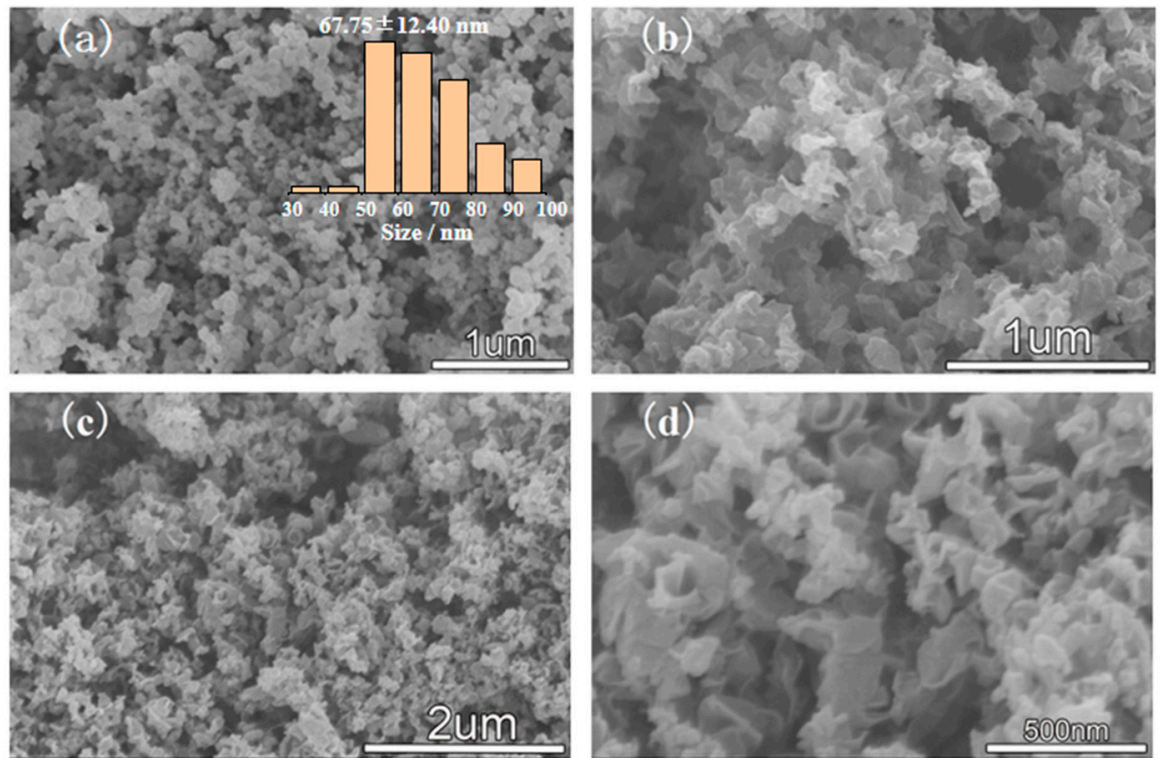

Figure 5. SEM images of the pure Si nanoparticles (a), pure tremelliform carbon nanosheets (b), silicon-carbon nanocomposite (c,d) prepared by DC magnetoelectric plasma under optimal conditions. Inset: size distribution of the Si nanoparticles. 
The XRD spectra of the silicon-carbon nanocomposite are shown in Figure 6a. The diffraction peaks at $28.4^{\circ}, 47.3^{\circ}$, and $56.1^{\circ}$ correspond to the (110), (220), and (311) crystal planes of Si nanoparticles, respectively [34-37]. Graphite (002) and (100) crystal planes were also found at $26.4^{\circ}$ and $42.2^{\circ}$, which indicates that a part of carbon in the silicon-carbon nanocomposite was graphitized [38]. The diffraction peaks of $\mathrm{SiC}$ were not found in the spectra, indicating that the composite prepared by plasma was composed of only Si nanoparticles and tremelliform carbon nanosheets, and the silicon and carbon are physically bound together, which is completely consistent with the SEM image of the silicon-carbon nanocomposite (Figure 4). Figure $6 \mathrm{~b}$ shows the Raman spectra of the silicon-carbon nanocomposite. A well-defined D band $\left(1343 \mathrm{~cm}^{-1}\right)$ is attributed to the amorphous structure of carbon, and the $\mathrm{G}$ band $\left(1573 \mathrm{~cm}^{-1}\right)$ associates with $\mathrm{sp}^{2}$-bonded corresponding to the graphitized carbon in the silicon-carbon nanocomposite [39]. The characteristic peak at $504 \mathrm{~cm}^{-1}$ corresponds to the crystalline $\mathrm{Si}$. However, there is no typical peak of $\mathrm{SiO}_{2}\left(\mathrm{SiO}_{2}\right.$ has a asymmetric peak at $460 \mathrm{~cm}^{-1}$, a sharp peak at $490 \mathrm{~cm}^{-1}$, and two broad features peaks at 800 and $1050 \mathrm{~cm}^{-1}$ ) [40], further indicating that the silicon-carbon nanocomposite prepared by the plasma method is mainly composed of tremelliform carbon nanosheets and Si nanoparticles.
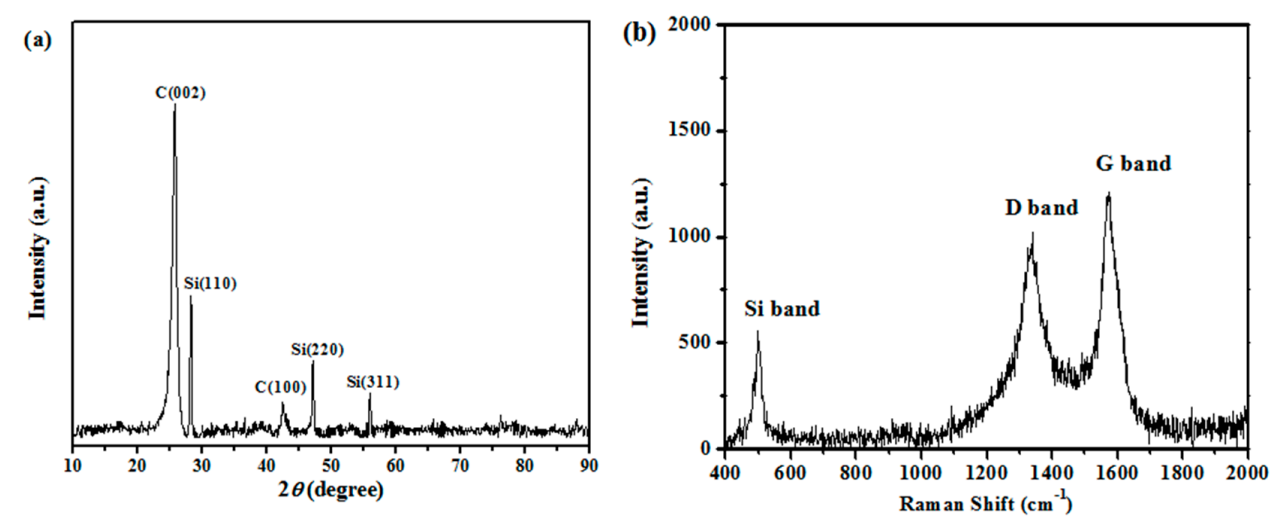

Figure 6. XRD pattern (a) and Raman pattern (b) of the silicon-carbon nanocomposite prepared by DC magnetoelectric plasma under optimal conditions.

\subsection{Electrochemical Performance of Silicon-Carbon Nanocomposite}

The electrochemical properties of the electrodes were measured by the EIS and CV measurements. Figure $7 \mathrm{a}$ shows the EIS of the electrodes after different cycles. The impedance spectrum consists of a semicircle, which is related to the charge-transfer impedance at the electrode-electrolyte interface in the high-frequency region, and a straight line, which implies the lithium diffusion impedance in the low frequency region. As the number of charge/discharge cycles increases, the diameter of the semicircle in the high-frequency region tends to increase. This is mainly due to the volume expansion of $\mathrm{Si}$ nanocomposite during the charge/discharge progress, which leads to the destruction of SEI film and the exposure of the Si nanocomposite surface. The formation of new SEI film consumes the electrolyte and thus increases the impedance. However, there is no significant difference among the three curves after 50 cycles. This indicates that the increase of interface impedance is limited during the cycles, and the SEI film formed is relatively stable [41], proving that the composite structure can efficiently alleviate the volumetric changes of Si nanocomposite.

Figure $7 \mathrm{~b}$ shows the initial five $\mathrm{CV}$ curves of the composite. In the cathodic scan of the first cycle curve (discharge processes), a cathodic peak located at $0.1 \mathrm{~V}\left(\mathrm{vs} . \mathrm{Li} / \mathrm{Li}^{+}\right.$) is related to the $\mathrm{Li}_{\mathrm{x}} \mathrm{Si}$ (amorphous) alloy formation from $\mathrm{Si}$ (crystalline) and a phase transition from $\mathrm{Li}_{\mathrm{x}} \mathrm{Si}$ (amorphous) to $\mathrm{Li}_{15} \mathrm{Si}_{4}$ (crystalline); a broad reductive peak at about $0.25 \sim 0.9 \mathrm{~V}$ (vs. $\mathrm{Li} / \mathrm{Li}^{+}$) corresponds to the decomposition reaction of electrolyte and the SEI film formation on the surface of the composite, which disappeared from the second cycle. Correspondingly, during the anodic scan (charge processes), the two anodic peaks at 0.36 and $0.52 \mathrm{~V}\left(\mathrm{vs} . \mathrm{Li} / \mathrm{Li}^{+}\right.$) are ascribed to the dealloying reactions from 
$\mathrm{Li}_{x} \mathrm{Si}$ (amorphous) or $\mathrm{Li}_{15} \mathrm{Si}_{4}$ (crystalline) to $\mathrm{Si}$ (amorphous). From the second cycle, a cathodic peak at about $0.2 \mathrm{~V}$ and the two anodic peak $(0.36$ and $0.52 \mathrm{~V})$ are characteristic of the phase transition between $\mathrm{Li}_{15} \mathrm{Si}_{4}$ (crystalline) and $\mathrm{Si}$ (amorphous) [42-44]. The increase in peak current is due to the continuous reaction of Si (crystalline) in the inner of the nanoparticles with Li during the repeated lithiation/delithiation $[45,46]$. The conclusion seems reasonable that the Si nanocomposite is the main reactant with $\mathrm{Li}$ and the main provider of Li storage capacity in the silicon-carbon nanocomposite.
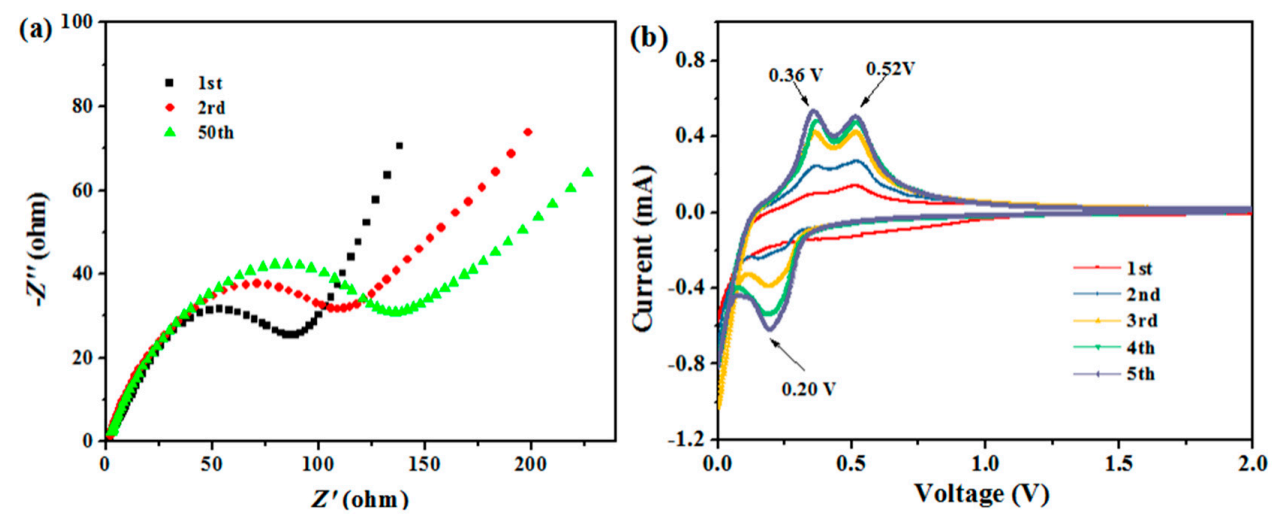

Figure 7. (a) Electrochemical impedance spectroscopy (EIS) of the silicon-carbon nanocomposite after different cycles, (b) cyclic voltammetry (CV) curves of the silicon-carbon nanocomposite from 0.01 to $2.0 \mathrm{~V}$ at a scanning rate of $0.1 \mathrm{mV} \mathrm{s}^{-1}$.

Figure 8a displays the charge/discharge profiles of the silicon-carbon nanocomposite for 1st, 2nd, and 50th cycle, respectively. The galvanostatic cycling was carried out at a current density of $150 \mathrm{~mA} \mathrm{~g}^{-1}$. The initial discharge and charge capacities of the silicon-carbon nanocomposite are 1469 and $1193 \mathrm{mAh} \mathrm{g}^{-1}$, respectively, and the coulombic efficiency of the first cycle is $81.2 \%$. The initial irreversible capacity is mainly due to the SEI film formation on the composite, and the irreversible process disappeared during the subsequent cycles. For the second cycle, the discharge and charge capacities of the electrode are 1217 and $1106 \mathrm{mAh} \mathrm{g}^{-1}$, respectively, and the coulombic efficiency increases to $90.8 \%$. After the second cycle, the coulombic efficiency rapidly reaches $99 \%$ and remains stable for 50 cycles. After 50 cycles, the discharge-specific capacity of the composite electrode is $1007 \mathrm{mAh} \mathrm{g}^{-1}$ with a high capacity retention of $68.6 \%$ as shown in Figure $8 \mathrm{~b}$, and the good cycling stability attributed to the silicon-carbon nanocomposite structure effectively alleviates the volumetric expansion during the cycles.
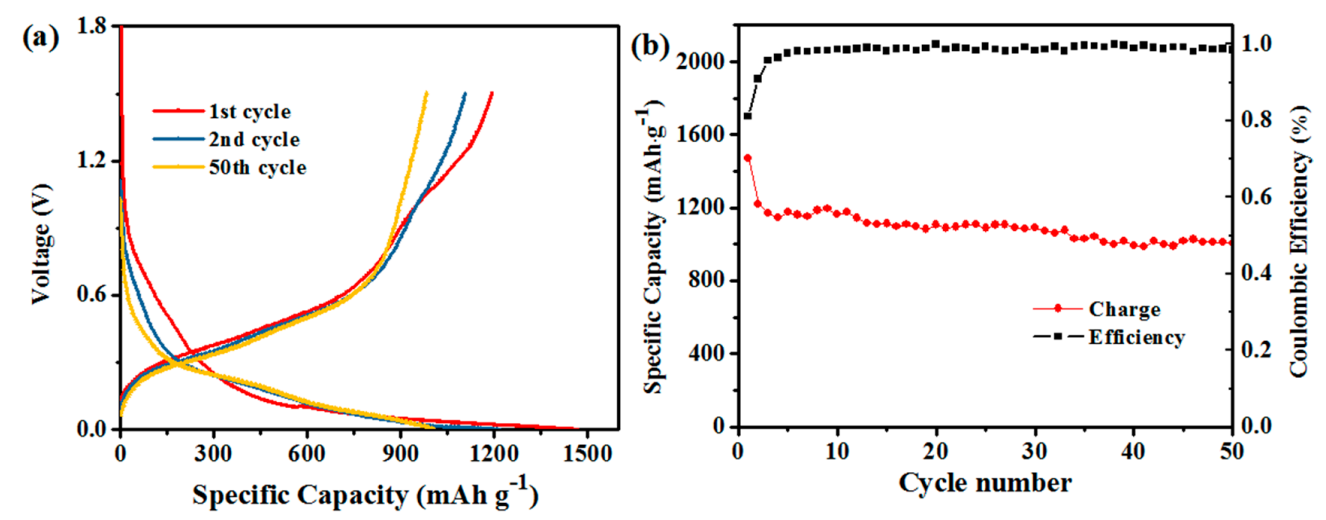

Figure 8. Charge/discharge profiles (a) and cycling performance $(\mathbf{b})$ of the silicon-carbon nanocomposite at $150 \mathrm{~mA} \mathrm{~g}^{-1}$ between 0.01 and $1.5 \mathrm{~V}$.

Figure 9 shows the rate performance of the silicon-carbon nanocomposite at different current densities from 150 to $3000 \mathrm{~mA} \mathrm{~g}^{-1}$. It can be seen that the silicon-carbon nanocomposite delivered 
the reversible capacities of $1118,1035,775,600$, and $414 \mathrm{mAh} \mathrm{g}^{-1}$ at the current densities of 150, 300, 750,1500 , and $3000 \mathrm{~mA} \mathrm{~g}^{-1}$, respectively. The reversible capacity quickly restores to $1010 \mathrm{mAh} \mathrm{g}^{-1}$, when the current density drops to $150 \mathrm{~mA} \mathrm{~g}^{-1}$, indicating the silicon-carbon composite has a good rate performance.

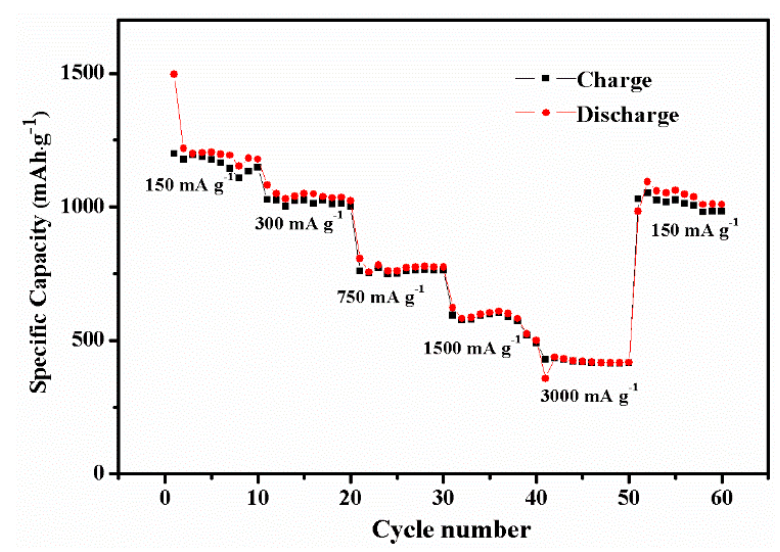

Figure 9. Rate capability of the silicon-carbon nanocomposite at different current densities between 0.01 and $1.5 \mathrm{~V}$.

\section{Conclusions}

In summary, the silicon-carbon nanocomposite was facilely synthesized by the one-step magnetoelectric plasma pyrolysis method. The effects of the ratio of silane, methane, and hydrogen on the properties of the composites were investigated in this paper. Under the optimized ratio of hydrogen/silane/methane (1:1:3), the silicon-carbon nanocomposite is composed of tremelliform carbon nanosheets and spherical $\mathrm{Si}$ nanoparticles and without $\mathrm{SiO}_{2}$ and $\mathrm{SiC}$ according to the XRD and Raman spectroscopy analysis. As anodes for LIBs, the tremelliform carbon nanosheets of silicon-carbon nanocomposite can efficiently alleviate the volume changes of Si nanoparticles during the cycles. The initial specific capacity of the silicon-carbon composite is $1469 \mathrm{mAh} \mathrm{g}^{-1}$ at a current density of $150 \mathrm{~mA} \mathrm{~g}^{-1}$ with a coulombic efficiency of $68.3 \%$, and the reversible capacity is stable at $1007 \mathrm{mAh} \mathrm{g}^{-1}$ after 50 cycles. Furthermore, in the rate performance test, when the current density returned from 3000 to $150 \mathrm{~mA} \mathrm{~g}^{-1}$, the specific capacity increased rapidly from 400 to $1010 \mathrm{mAh} \mathrm{g}^{-1}$. The good specific capacity, cycling stability, and rate performance may be attributed to the efficient structure of the silicon-carbon nanocomposite.

Author Contributions: Conceptualization, R.H.; Data Curation, M.G.; Formal Analysis, F.W.; Funding Acquisition, R.H.; Investigation, F.W.; Methodology, F.W.; Project Administration, R.H.; Software, M.G.; Supervision, R.H.; Validation, R.H.; Visualization, M.G.; Writing-Original Draft, F.W.; Writing-Review \& Editing, X.L. All authors have read and agreed to the published version of the manuscript.

Funding: This research was financially supported by the National Natural Science Foundation of China (NSFC, No. 21246002), Minjiang Scholarship of Fujian Province (No. Min-Gaojiao[2010]-117), Central-government Guided Fund for Local Economic Development (No. 830170778), R\&D Fund for Strategic Emerging Industry of Fujian Province (No. 82918001), and International Cooperation Project of Fujian Science and Technology Department (No. 830170771).

Conflicts of Interest: The authors declare no conflict of interest.

\section{References}

1. Choi, J.W.; Aurbach, D. Promise and reality of post-lithium-ion batteries with high energy densities. Nat. Rev. Mater. 2016, 1, 1-13. [CrossRef]

2. Bruce, P.; Scrosati, B.; Tarascon, J.M. Nanomaterials for rechargeable lithium batteries. Angew. Chem. Int. Ed. 2008, 47, 2930-2946. [CrossRef] [PubMed]

3. Dunn, B.; Kamath, H.; Tarascon, J.M. Electrical Energy Storage for the Grid: A Battery of Choices. Science 2011, 334, 928-935. [CrossRef] [PubMed] 
4. Winter, M.; Jürgen, O.B.; Spahr, M.E.; Novak, P. Insertion electrode materials for rechargeable lithium batteries. Adv. Mater. 1998, 10, 725-763. [CrossRef]

5. Endo, M.; Kim, C.; Nishimura, K.; Fujino, T.; Miyashita, K. Recent Development of Carbon Materials for Li Ion Batteries. Carbon 2000, 38, 183-197. [CrossRef]

6. Zhou, M.; Liu, Y.; Chen, J.; Yang, X.; Mater, J. Double shelled hollow $\mathrm{SnO}_{2}$ /polymer microsphere as a high-capacity anode material for superior reversible lithium ion storage. J. Mater. Chem. A 2015, 3, 1068-1076. [CrossRef]

7. Zhu., Z.; Wang, S.; Du, J.; Jin, Q.; Zhang, T.; Cheng, F. Ultrasmall sn nanoparticles embedded in nitrogen-doped porous carbon as high-performance anode for lithium-ion batteries. Nano Lett. 2014, 14, 153-157. [CrossRef]

8. Huang, X.; Yang, J.; Mao, S.; Chang, J.; Hallac, P.B.; Fell, C.R.; Metz, B.; Jiang, J.; Hurley, P.T.; Chen, J. Controllable synthesis of hollow $\mathrm{Si}$ anode for long-cycle-life lithium-ion batteries. Adv. Mater. 2014, 26, 4326-4332. [CrossRef]

9. Zhou, X.; Guo, Y.G. A peo-assisted electrospun silicon-graphene composite as an anode material for lithium-ion batteries. J. Mater. Chem. A 2013, 1, 9019-9023. [CrossRef]

10. Yang, X.Y.; Tachikawa, N.; Katayama, Y.; Li, L.; Yan, J.W. Effect of the pillar size on the electrochemical performance of laser-induced silicon micropillars as anodes for lithium-ion batteries. Appl. Sci. 2019, 9, 3623. [CrossRef]

11. Poizot, P.; Laruelle, S.; Grugeon, S.; Dupont, L.; Tarascon, J.M. Nano-sized transition-metal oxides as negative-electrode materials for lithium-ion batteries. Nature 2000, 407, 496-499. [CrossRef] [PubMed]

12. Peng, L.; Zhang, H.J.; Bai, Y.J.; Zhang, Y.; Wang, Y. A self-supported peapod-like mesoporous $\mathrm{TiO}_{2}-\mathrm{C}$ array with excellent anode performance in lithium-ion batteries. Nanoscale 2015, 7, 8758-8765. [CrossRef]

13. Wang, B.; Li, X.; Zhang, X.; Luo, B.; Jin, M.; Liang, M.; Dayeh, S.A.; Picraux, S.T.; Zhi, L. Adaptable silicon-carbon nanocables sandwiched between reduced graphene oxide sheets as lithium ion battery anodes. Acs Nano 2013, 7, 1437-1445. [CrossRef] [PubMed]

14. Jia, H.P.; Zheng, J.M.; Song, J.K.; Luo, L.L.; Zhang, J.-G. A novel approach to synthesize micrometer-sized porous silicon as a high performance anode for lithium-ion batteries. Nano Energy 2018, 50, 589-597. [CrossRef]

15. Yu, Y.; Gu, L.; Zhu, C.; Tsukimoto, S.; van Aken, P.A.; Maier, J. Reversible storage of lithium in silver-coated three-dimensional macroporous silicon. Adv. Mater. 2010, 22, 2247-2250. [CrossRef] [PubMed]

16. Li, H.; Lu, C.; Zhang, B. A straightforward approach towards Si@C/graphene nanocomposite and its superior lithium storage performance. Electrochim. Acta 2014, 120, 96-101. [CrossRef]

17. Feng, K.; Li, M.; Liu, W.W.; Kashkooli, A.G.; Chen, Z.W. Silicon-based anodes for lithium-ion batteries: From fundamentals to practical applications. Small 2018, 14, 1702737-1702769. [CrossRef]

18. Liu, X.; Du, Y.; Hu, L.; Zhou, X.; Li, Y.; Dai, Z.; Bao, J. Understanding the effect of different polymeric surfactants on enhancing the silicon/reduced graphene oxide anode performance. J. Phys. Chem. C 2015, 119, 5848-5854. [CrossRef]

19. Kim, J.; Yang, S.Y.; Kim, K.Y. Improving the microstructure and electrochemical performance of carbon nano-fibers containing graphene-wrapped silicon nanoparticles as a li-ion battery anode. J. Power Sources 2015, 273, 404-412. [CrossRef]

20. Park, M.S.; Park, E.; Lee, J.; Jeong, G.; Kim, K.J.; Kim, J.H.; Kim, Y.J.; Kim, H. Hydrogen silsequioxane-derived $\mathrm{Si} / \mathrm{SiO}_{\mathrm{x}}$ nano-spheres for high-capacity lithium storage materials. Acs Appl. Mater. Inter. 2014, 6, 9608-9613. [CrossRef]

21. Kim, S.Y.; Kim, B.H.; Yang, K.Y. Preparation and electrochemical characteristics of a polyvinyl pyrrolidone-Stabilized Si/carbon composite nanofiber anode for a lithium ion battery. J. Electroanal. Chem. 2013, 705, 52-56. [CrossRef]

22. Liu, N.; Wu, H.; McDowell, M.T.; Yao, Y.; Wang, C.; Cui, Y. A yolk-shell design for stabilized and scalable li-ion battery alloy anodes. Nano Lett. 2012, 12, 3315-3321. [CrossRef] [PubMed]

23. Pan, L.; Wang, H.; Gao, D.; Chen, S.; Tan, L.; Li, L. Facile synthesis of yolk-shell structured Si-C nanocomposites as anodes for lithium-ion batteries. Chem. Commun. 2014, 50, 5878-5880. [CrossRef]

24. Ng, S.H.; Wang, J.; Wexler, D.; Konstantinov, K.; Guo, Z.P.; Liu, H.K. Highly reversible lithium storage in spheroidal carbon-coated silicon nanocomposites as anodes for lithium-ion batteries. Angew. Chem. Int. Ed. 2006, 45, 6896-6899. [CrossRef] [PubMed]

25. Kim, S.Y.; Lee, J.; Kim, B.H.; Kim, Y.J.; Yang, K.S.; Park, M. A facile synthesis of carbon-coated silicon/graphite spherical composites for high-performance lithium-ion Batteries. Acs Appl. Mater. Inter. 2016, 8, 12109-12117. [CrossRef] 
26. Wang, L.Y.; Liu, Z.J.; Guo, Q.G.; Guo, X.H.; Gu, J.J. Electrochemical properties of a silicon nanoparticle/hollow graphite fiber/carbon coating composite as an anode for lithium-ion batteries. Rsc Adv. 2017, 7, 36735-36743. [CrossRef]

27. Saint, J.; Morcrette, M.; Larcher, D.; Laffont, L.; Beattie, S.; Pérès, J.P.; Talaga, D.; Couzi, M.; Tarascon, J.M. Towards a fundamental understanding of the improved electrochemical performance of silicon-carbon composites. Adv. Funct. Mater. 2007, 17, 1765-1774. [CrossRef]

28. Ng, S.H.; Wang, J.; Wexler, D.; Chew, S.Y.; Liu, H.K. Amorphous carbon-coated silicon nanocomposites: A low-temperature synthesis via spray pyrolysis and their application as high-capacity anodes for lithium-ion batteries. J. Phys. Chem. C 2007, 111, 11131-11138. [CrossRef]

29. Wang, F.; Hong, R.Y. Continuous preparation of structure-controlled carbon nanoparticle via arc plasma and the reinforcement of polymeric composites. Chem. Eng. J. 2017, 328, 1098-1111. [CrossRef]

30. Park, J.; Heberlein, J.; Pfender, E.; Candler, G.; Chang, C.H. Two-dimensional numerical modeling of direct-current electric arcs in nonequilibrium. Plasma Chem. PlasmaP. 2008, 28, 213-231. [CrossRef]

31. Wang, F.; Sun, D.L.; Hong, R.Y.; Kumar, M.R. Preparation of carbon nanoparticles by plasma arc discharge under fluidized dynamic equilibrium. J. Nanopart. Res. 2006, 18, 148-162. [CrossRef]

32. Zhong, R.P.; Hong, R.Y. Continuous preparation and formation mechanism of few-layer graphene by gliding arc plasma. Chem. Eng. J. 2020, 387, 124102-124111. [CrossRef]

33. Li, B.; Nan, Y.L.; Cao, H.; Yan, P.; Zhao, S.R.; Zhao, X.; Song, X.L. Arc plasma-assisted hydrogenation of few-layer graphene in methane hydrogen atmospheres. Diam. Relat. Mater. 2017, 76, 44-49. [CrossRef]

34. Doğan, İ.; Weeks, S.L.; Agarwal, S.; van de Sanden, M.C.M. Nucleation of silicon nanocrystals in a remote plasma without subsequent coagulation. J. Appl. Phys. 2014, 115, 244301-244309. [CrossRef]

35. Seo, M.H.; Park, M.; Lee, K.T.; Kim, K.; Kim, J.; Cho, J. High performance Ge nanowire anode sheathed with carbon for lithium rechargeable batteries. Energ. Environ. Sci. 2011, 4, 425-428. [CrossRef]

36. Lee, J.I.; Choi, N.S.; Park, S. Highly stable Si-based multicomponent anodes for practical use in lithium-ion batteries. Energ. Environ. Sci. 2012, 5, 7878-7882. [CrossRef]

37. Li, Z.; Huang, J.J.; Zhang, Z.Z.; Zhao, F.X.; Wu, Y. Preparation of high purity nano-silicon powders by direct current arc plasma evaporation method. Mater. Sci. Eng. B 2018, 229, 6-12. [CrossRef]

38. Lu, S.; Blanco, C.; Appleyard, S.; Hammond, C.; Rand, B. Texture studies of carbon and graphite tapes by XRD texture goniometry. J. Mater. Sci. 2002, 37, 5283-5290. [CrossRef]

39. Yin, L.; Wang, J.; Lin, F.; Yang, J.; Nuli, Y. Polyacrylonitrile/graphene composite as a precursor to a sulfur-based cathode material for high-rate rechargeable Li-S batteries. Energ. Environ. Sci. 2012, 5, 6966-6972. [CrossRef]

40. Li, B.; Yu, D.; Zhang, S.L. Raman spectral study of silicon nanowires. Phys. Rev. B 1999, 59, 1645-1648. [CrossRef]

41. Guo, J.C.; Sun, A.; Chen, X.L.; Wang, C.S.; Manivannan, A. Cyclability study of silicon-carbon composite anodes for lithium-ion batteries using electrochemical impedance spectroscopy. Electrochim. Acta 2011, 56, 3981-3987. [CrossRef]

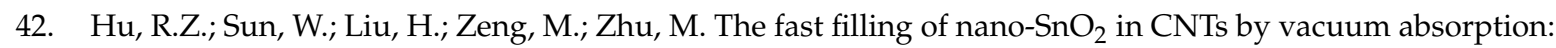
A new approach to realize cyclic durable anodes for lithium ion batteries. Nanoscale 2013, 5, 11971-11979. [CrossRef] [PubMed]

43. Hassoun, J.; Lee, K.S.; Sun, Y.K.; Scrosati, B. An advanced lithium ion battery based on high performance electrode materials. J. Am. Chem. Soc. 2011, 133, 3139-3143. [CrossRef]

44. Sun, W.; Hu, R.Z.; Zhang, H.Y.; Wang, Y.K.; Yang, L.C.; Liu, J.W.; Zhu, M. A long-life nano-silicon anode for lithium ion batteries: Supporting of graphene nanosheets exfoliated from expanded graphite by plasma-assisted milling. Electrochim. Acta 2016, 187, 1-10. [CrossRef]

45. Wu, J.X.; Qin, X.Y.; Zhang, H.R.; He, Y.B.; Li, B.H.; Ke, L.; Lv, W.; Du, H.D.; Yang, Q.H.; Kang, F.Y. Multilayered silicon embedded porous carbon/graphene hybrid film as a high performance anode. Carbon 2015, 84, 434-443. [CrossRef]

46. Zhang, Y.Y.; Li, K.; Ji, P.Y.; Chen, D.Q.; Zeng, J.; Sun, Y.Z.; Zhang, P.; Zhao, J.B. Silicon-multi-walled carbon nanotubes-carbon microspherical composite as high-performance anode for lithium-ion batteries. J. Mater. Sci. 2016, 52, 1-12. [CrossRef]

(C) 2020 by the authors. Licensee MDPI, Basel, Switzerland. This article is an open access article distributed under the terms and conditions of the Creative Commons Attribution (CC BY) license (http://creativecommons.org/licenses/by/4.0/). 